\title{
COMENTÁRIO: UMA PROFUNDIDADE TEMPORAL NO MUNDO ESTÉTICO
}

\section{Osvaldo Fontes Filho ${ }^{1}$}

Referência do texto comentado: ALVARENGA, Rodrigo. A carnalidade de outrem e o logos do mundo estético em Merleau-Ponty. Trans/Form/Ação: revista de filosofia da Unesp, vol. 43, n. 4, p. 313 - 336, 2020.

Em dado momento de seu texto, Rodrigo Alvarenga explica como uma "presença estranha" destitui o artista de seu papel central no processo de criação. Por força de uma precessão recíproca da visão e do visível, e à semelhança do que ocorre na relação entre ego e alter ego, os polos de toda experiência sensível e de expressão acusam sua mútua deiscência. Como bem observa Alvarenga, em função de um estranhamento mútuo, a relação do artista com sua obra "transcende os limites da distinção clássica do sujeito e do objeto".

A observação poderia se prestar a uma interlocução com o texto de Camargo (2020) e sua impaciência quanto aos dualismos persistentes no pensamento de Merleau-Ponty. Em todo caso, carece perguntar: a experiência de outrem como estranho, como um fantasma, salva a ontologia da carne dos "problemas insolúveis" advindos da inicial fenomenologia da percepção? Mas qual a fortuna dessa perspectiva de estranhamento, em particular, na "intersubjetividade intermediada pela arte", para reter as derradeiras palavras de Alvarenga? A Carne, declarada selvagem em um desdobramento estético

\footnotetext{
${ }_{1}$ Docente no Departamento de História da Arte e no Programa de Pós-Graduação em História da Arte da Escola de Filosofia, Letras e Ciência Humanas da Universidade Federal de São Paulo. Doutor em filosofia pela Universidade de São Paulo. oriid.org/0000-0002-2358-3902. E-mail: osvaldo. fontes@unifesp.br. São Paulo, SP, Brasil.
}

http://dx.doi.org/10.1590/0101-3173.2020.v43n4.21.p337

This is an open-access article distributed under the terms of the Creative Commons Attribution License. 
da fenomenologia, seria "tenra demais", como afirma Deleuze (1991, p. 232), para revelar "o fundo da natureza inumana sobre o qual se instala o homem"?

Em $O$ olho e o espirito, Merleau-Ponty trata de uma "vidência" que consiste em "ver mais do que se vê", uma vez que o invisível seria "o relevo e a profundidade do visível”. A vidência, em última instância, presentificaria um ausente como uma "quase-presença" (MERLEAU-PONTY, 1993, p. 23), não como uma presença fugidia, mas como "a pregnância do invisível no visível”. Pregnância que se afirma eficaz e insistente, como a " carne do imaginário" (MERLEAU-PONTY, 1996, p. 173).

Creio que seria devido, nos termos de um questionamento radical entre a filosofia e o estatuto dessa carnalidade do imaginário que se imiscui nas experiências sensíveis - não seria este, direta ou indiretamente, motivo comum a nossos dois autores? - referir o que Georges Didi-Huberman - um dos partidários, hoje, desse tipo de questionamento - propóe: um “modelo temporal capaz de explicar a 'origem' no sentido benjaminiano, ou a 'sobrevivência' no sentido de Warburg”. Em suma, um modelo capaz de explicar a historicidade dos fatos culturais como eventos da memória involuntária (DIDI-HUBERMAN, 2000, p. 239). Nesse sentido, perguntemos: poderse-ia falar de uma efetiva herança merleau-pontyana, daquele "estranhamento nas relaçóes com o mundo e com outrem" que Alvarenga comenta, nos modos contemporâneos de interrogação da memória em obra nas imagens da cultura?

Há, no último Merleau-Ponty - ainda que apenas esboçada -, a tese de uma precessão recíproca da visão e do visível. Alvarenga não deixa de comentála, evidentemente. Mas será que não se poderia tomar essa tese paradoxal -a qual leva a sério "as consequências extravagantes" da interrogação da visão como constitutiva do "modelo temporal" evocado por Didi-Huberman, a partir de Benjamin e Warburg? Se assim for, isso talvez nos conduza a uma compreensão mais aprofundada da questão da presença das imagens, hoje; questão sobre a qual se pode bem afirmar, na verdade, o que o próprio Merleau-Ponty sustentou acerca da pintura, em $O$ olho e o espirito, a saber, que ela "confunde todas as nossas categorias" - essência e existência, imaginário e real, visível e invisível - e, com elas, a própria identidade da filosofia.

É este, em toda a sua amplitude, o desafio que Merleau-Ponty parece ter estabelecido; é o desafio que, de nossa parte, não podemos deixar de aceitar. Enfim, é ele que me sugerem os textos com os quais aqui dialogo, tanto o de Rodrigo Alvarenga quanto o de Camargo (2020). A “invisibilidade 
de um olhar outro que me atinge sem que eu tenha condiçôes de dizer de onde tenha partido" bem pode ser originária da imagem (das figuras da arte em geral), quando dela se vê extirpada a transcendência aparente do $\mathrm{Eu}-\mathrm{o}$ "protagonismo da subjetividade constituinte", nos termos de Alvarenga.

Nos últimos anos, Didi-Huberman tem-nos mostrado incansavelmente como a imagem pode carregar em si um fundo de inquietação, que não é intencionalidade, a partir do qual a experiência do olhar se mostra uma experiência de despossessão. Para investigar esse poder da imagem de se apoderar do olhar, de se verificar verdadeiro tesouro de sobredeterminaçóes psíquicas e culturais, o filósofo-historiador recorre ao conceito benjaminiano de aura. A aura seria uma espécie de atributo visual da obra de arte que se manifesta na dinâmica entre proximidade e distância, dinâmica que revela uma inevitável operação de perda implicada na visualidade: a aparição de algo que só aparece, tornando-se ao mesmo tempo distante, algo único e estranho, algo que impede o reconhecimento, deslegitima a ordem do saber. Didi-Huberman não deixa de evocar um segundo aspecto da aura: "o poder do olhar atribuído ao próprio olhado pelo olhante: "isto me olha" (DIDIHUBERMAN, 1998, p. 148, grifo do autor).

Importa aqui sublinhar como a formulação, em $O$ olho e o espirito, dessa reciprocidade a investe de uma forma temporal, já que a "precessão" é caracterizada precisamente como um movimento de antecipação mútua entre os termos que estão implicados nesta relação. Em outros termos, haveria uma precessão do ausente sobre o presente - já que o ausente alimenta o olhar, fazendo-nos ver o presente sempre investido de latências, conforme mostrava Warburg -, assim como haveria uma precessão do presente sobre o ausente, investindo-o de urgência crítica junto ao presente, como preconizava Benjamin. Temos, pois, nas relaçóes estabelecidas pelo olhar (figura-fundo, proximidadelonjura, eu-outro), o primado da indecidibilidade - o que Alvarenga comenta em termos de simultaneidade dos tempos presente e passado.

Mas o mais importante a notar parece ser o fato de essa precessão recíproca escavar no tempo uma profundidade bem particular. A propósito, em $O$ olho e o espirito, Merleau-Ponty (1993, p. 86) evoca o "fundo imemorial do visível”. É nesse sentido, creio, que seria necessário pensar a profundidade temporal, segundo o faz Rodrigo Alvarenga. Tanto mais que ele não deixa de denotar seu caráter mítico. De fato, na chave freudiana do inconsciente, como "indestrutíveis", "atemporais", o passado é dito pertencer a um tempo mítico, aquele “em que certos eventos 'do início' guardam uma eficácia 
continuada” (MERLEAU-PONTY, 1964, p. 43). É esse tipo particular de tempo "imemorial" que opera em nosso inconsciente e do qual podemos ler a "eficácia continuada", no que Didi-Huberman afirma ser "a indestrutibilidade, [...] a transformabilidade e o anacronismo dos eventos da memória" (DIDIHUBERMAN, 2000, p. 239-240). Dito de outro modo, trata-se da temporalidade, no interior da qual as experiências sensíveis são elaboradas de modo involuntário - por uma espécie de "esquecimento ativo" (MERLEAUPONTY, 1996, p. 115) - como "essências carnais" (MERLEAU-PONTY, 1993, p. 35), como "ideias sensíveis” (MERLEAU-PONTY, 1964, p. 196198). Estas últimas se introjetam miticamente e se sedimentam enquanto tais; permanecem sempre ativas num "passado arquitetônico". O tempo mítico é, portanto, o tempo particular em que vivem as assim chamadas "ideias sensíveis”. Merleau-Ponty sugere por aí não somente que essas ideias são inseparáveis de sua apresentação sensível (ou seja, de suas imagens visuais, mesmo linguageiras), mas sobretudo que elas são instituídas por essas mesmas imagens, como sua própria profundidade. Em outras palavras, o "princípio encarnado que importa um estilo de ser em todos os lugares onde se encontra uma parcela sua", comentado por Alvarenga.

Assim, permito-me uma vez mais apontar para as "consequências extravagantes" da interrogação merleau-pontyana da visão. Desta feita, para sugerir que elas constituem uma efetiva fonte para o desenvolvimento de um "modelo temporal" das migraçóes da imagem, ao longo do tempo como a entendem alguns autores da atual Teoria da Arte francesa. Este seria, como já foi frisado acima, um modelo capaz de explicar a história pelos eventos da memória, e não pelos fatos culturais; modelo capaz, mesmo, de acionar um inconsciente do tempo. A perspectiva, diga-se, possui capacidade de revisão epistemológica. A lembrar como Didi-Huberman alerta para os paradoxos abertos pelas potências fantasmáticas da imagem; para o que abala as relações causais, desmantela as cronologias e as clássicas compartimentalizaçóes dos saberes.

Já se observou como um retorno a Merleau-Ponty está na base de uma Teoria da Arte francesa, a qual atenta à dupla necessidade do pensamento estético: ser filosófico e antropológico. Assim, ela é ciente de que "entre aquele que olha e aquilo que é olhado [...] é preciso um vazio que seja o não-lugar de articulação dessas duas instãncias envolvidas na percepção e no encontro entre 'olhante' e 'olhado', olhante e olhado que pertencem tanto ao âmbito da obra e da imagem quanto ao do antropos" (HUCHET, 1998, p. 22; grifo do autor). 
Tal perspectiva sobre a qual se pode refletir, quiçá, à luz dos textos de Rodrigo Alvarenga e de Camargo (2020), mesmo porque me parece que a obra de Merleau-Ponty, exaustivamente analisada, necessita ser mais bem examinada, a partir de seus desdobramentos, que, bem lembra Alvarenga, "transcende[m] todo e qualquer tipo de categorização".

\section{REFERÊNCIAS}

CAMARGO, Jeovane. Sobre as consequências filosóficas do primado da percepção em Merleau-Ponty.Trans/Form/Açáa: revista de filosofia da Unesp, vol. 43, Número Especial, p. 231-256, 2020

DELEUZE, Gilles. Qu'est-ce que la philosophie? Paris: Minuit, 1991.

DIDI-HUBERMAN, Georges. Devant le temps. Histoire de l'art et anachronisme des images. Paris: Minuit, 2000.

DIDI-HUBERMAN, Georges. O que vemos, o que nos olha. Sáo Paulo: Ed. 34, 1998

HUCHET, Stéphane. Passos e caminhos de uma teoria da arte. In: Didi-Huberman, G. O que vemos, o que nos olha. Trad. Paulo Neves. São Paulo: Editora 34, 1998, p.7-23.

MERLEAU-PONTY, Maurice. Le visible et l'invisible. Paris: Gallimard, 1964.

MERLEAU-PONTY, Maurice. Notes des cours au Collège de France 1958-1959 et 1960-1961. Paris: Gallimard, 1996.

MERLEAU-PONTY, Maurice. L’oeil et l'esprit. Paris: Gallimard, 1993. 
FONTES FILHO, O.

Recebido: $02 / 11 / 2020$

Aceito: 06/11/2020 